\title{
USE OF A LEARNING MANAGEMENT SYSTEM FOR ELECTRONIC SUBMISSION AND MARKING OF A REFLECTION JOURNAL
}

\author{
Alan L Steele ${ }^{1}$ and Dragana Polovina-Vukovic ${ }^{2}$ \\ Dept. of Electronics ${ }^{1}$ and Educational Development Centre ${ }^{2}$, Carleton University, \\ 1125 Colonel By Drive, Ottawa, ON, K1S 5B6, Canada \\ alan.steele@carleton.ca
}

\begin{abstract}
A third year one-semester design project in electronic engineering has required students to individually keep a reflection journal and submit entries weekly. Previously, to encourage the writing of such a journal any form of submission was accepted, whether in a notebook, individual sheets of paper, document files or even emails. Such a varied form can become a logistical problem and with the class increasing to above 70 students this became difficult to organize and even physically carry (in the case of notebooks) for marking. It was decided to move to an electronic format for writing and submitting journal entries, using a learning management system (LMS). This use of a standard form of electronic submission could potentially inhibit the writing of reflection journal entries and consequently detract from the goal of developing metacognitive skills in students. This paper considers the challenges and degree of success in using an LMS based reflection journal system. It was seen that the response rate of the reflections was good and little difference was seen in the quality of reflections from the previous year with the paper based system. Sketches and circuits were infrequently seen, but the electronic medium did allow photographs to be included in the reflections. A survey was conducted for the student opinion on the reflection journals. From the 30\% of the class response, 58\% agreed that the journal use helped with their reflection but 59\% viewed the process of producing the journals a burden. The benefit to the instructor of using the LMS was significant, allowing security, legibility plus easy access and marking. The type of journal entries seen were similar to previous years with some good reflections by a few and many providing weak reflections and just describing what was done. It appears the LMS is a valid route to use for reflection journaling in this type of project course. Future focus may be on ways of encouraging and developing the reflection process.
\end{abstract}

Keywords: Reflection journal, metacognition, deep learning, engineering project.

\section{INTRODUCTION}

\subsection{Motivation}

In 2013 a new third year project was introduced into the Electrical Engineering program at Carleton University. This is a mandatory course that was included to be, in part, a preparation for the final year project as well as developing and consolidating technical and presentation skills. Student projects are done in groups and the projects are conceived by the students after some basic introduction to micro-controllers. In the first year of running the course a mostly paper-based system was used with the reflection journals (some submissions were emailed in). The collection and marking of 47 paperbased journals proved to be cumbersome. It was decided to standardize and simplify the collection of the journals by using the learning management system (LMS). This had the added benefit of simplifying the marking to the rubric and collation of the marks.

\subsection{Literature review}

In 1910 John Dewey [4] published his book "How We Think", which introduced a powerful notion of reflection as a "meaning-making process, which moves a learner from one experience into the next with deeper understanding of its relationships with and connections to other experiences and ideas, and which makes continuity of learning possible" [11]. Since then many educators introduced reflective writing as a necessary requirement in their classrooms in order to help students achieve a higher level of knowledge and sharpen their critical thinking skills. Many authors $[2,3,12]$ see reflection as a process in which deep level learning and thinking takes place and which is a necessary ingredient for becoming an active and critical learner. According to Mezirow [7], Schon [12], and Brookfield [2], reflective writing helps students develop and clarify connections between their prior and new knowledge. It also helps them become reflective practitioners once they begin their professional life. As Jarvis [5] points out: 
"Reflective practice is something more than thoughtful practice. It is that form of practice that seeks to problematize many situations of professional performance so that they can become potential learning situations and so the practitioners can continue to learn, grow and develop in and through practice” (p.180). [5]

Reidsema, Goldsmith and Mort [10] investigated reflective writing of the final year engineering students as the way of formation of their professional identities and their preparedness for lifelong learning and concluded that reflective writing "allows the student to engage with their beliefs, values, uncertainties, desires and questions and to clarify what they know and more importantly, do not know about a situation” (p. 4). These authors also argue that: "in relation to Blooms Taxonomy of Cognitive Skills, written reflection asks students to display higher order skills of evaluation (logical consistency) and synthesis (structuring)" (Ibid.), which is a necessary factor in the formation of their professional identity (Ibid.). [10]

While many authors talk about benefits of reflective journal writing in different disciplines, some challenges have also been described. In 2007 Brodie [1] conducted a study with the goal to examine benefits of the reflective writing exercise for distance engineering students at the University of Southern Queensland. The results showed that the "reflective writing and the reflection process are not easy skills to acquire" and that "guidance, feedback and continuous monitoring for students and teaching staff is required” (p. 7). Brodie's study [1] also showed that about $10 \%$ of students were successful in achieving a high level of reflection; the rest of them was not comfortable with reflective writing and restricted their written journals to a simple retelling of events and or facts. The author concludes that "additional guidance was required for developing students' competences in reflective writing (p. 5) [1].

Jennifer Moon [8] argues that there are many purposes of reflective journals, such as: recording experience, facilitating learning, developing critical thinking, increasing ownership of learning, and encouraging metacognition, among others (p. 4). She also argues that "a two-stage guidance process to reflection may be helpful to students" and that "multiple approaches providing different ideas and activities around reflection seem to be more successful than attempts at verbal instruction" (p. 6) [8].

While there is a vast amount of literature exploring benefits of a hardcopy of reflective journals in different disciplines, very few authors explored possible benefits and challenges of online reflective journals. Palmer, Holt and Bray [9] conducted a study, which investigated student perception of online journals in a fourth-year engineering management course. The findings showed that students felt that " "most useful' aspects of online journal were the 'enforced' continued revisions of course material” (p. 730); however, students reported problems related to the use of LMS as 'least useful' aspect of reflective journaling activity (Ibid.). Similarly, Smith, Mills and Myers [13] found some weaknesses of the online tools used for reflective journaling in a first year large engineering course, specifically in terms of logistics, both for students and course facilitators. While blogs, which were used as reflective journals, were straightforward to use, they were not adaptable for organizing sections of guided students' responses, and course instructors found it difficult to access multiple pages for each student, which resulted in an inadequate feedback provided to students (p. 8) [13].

\subsection{Research questions}

This study aims to contribute to the under-researched field of online reflective journaling explores possible challenges and degree of success in using an LMS based reflection journal system. Some of the research questions can be stated as follows: does online mode of reflective journaling affect the student response rate? How easy or challenging is for both students and instructors to use the online system? Is the quality of students' reflection affected by the medium? Is the inclusion of diagrams and sketches, which are so easily done by hand, pen and paper, limited with the use of an electronic format? Are there restrictions with the electronic form that counters the organizational benefit of using this format? Conversely and more philosophically, as engineering students will through their future careers move more completely to a universal paperless working environment, is the learning and development of an electronic journaling process a beneficial and necessary skill to learn and adopt?

\section{METHODOLOGY}

\subsection{The course}

The course within which the study was conducted is a one term, group project in the third year of an Electrical Engineering program. The course is mandatory and had prior to this study been run only once before under a very similar format.

Students in groups determine their own projects, having been introduced to a simple microcontroller. They spend six hours per week in the laboratory with two hours per week in a classroom. The assessment is split across a number of reports, presentations to the full class, the technical achievements of the project, and also a reflection journal.

\subsection{The reflection journal}


Because the students are often embarking on their first group project and learning about project and time management, the reflection journal was introduced. This was to encourage reflection on their project and to attempt to develop metacognition when undertaking work in their program area. For most, if not all, this was the first time for keeping a reflection journal.

In the first and previous running of the course to encourage the keeping of a reflection journal any format of a journal was accepted, such notebooks, loose leaf paper or even emails. This did prove to be cumbersome with the number of books and papers submitted. In that first year there were 47 students. Reading and commenting on the reflections took time and the journal collection had to be moved and stored safely. Delaying in the assessment of an entry and consequently not returning the journal could result in a delayed subsequent reflection. With an anticipated growth in the class number an alternative method of reflection journal management was sought. This led to the use of the LMS, for online submission, marking and storage.

\subsection{The learning management system}

In 2013 the transition to a new (LMS) was completed at Carleton University. The new LMS is Moodle and it has many features found in other LMS including the ability to submit and grade students work. Using a weekly format for the main course LMS webpage all relevant course materials were added there. No other website was used. Besides course documents and assignments, the LMS page also had extra material such as relevant news articles or videos relating to electronics and circuit design.

A reflection journal entry was added to each week of the LMS page, except for the reading week, when no journal was required. Students were given an extra week to enter their journal. The LMS provides a WYSIWIG type editor for writing, with the ability to add image files. This flexibility did offset the concern that moving away from paper could restrict the use of sketches or diagrams in the journal entries.

To assist the students in using the LMS, instruction on using the journal entry was given in in an early class. Attention was paid on using the tool to write an entry, draft saving and submission, as well as how to insert images.

\section{RESULTS}

\subsection{Reflection entries and marking}

Reflections were required weekly and they varied in length from 100 words to a few over 1000 words, with the

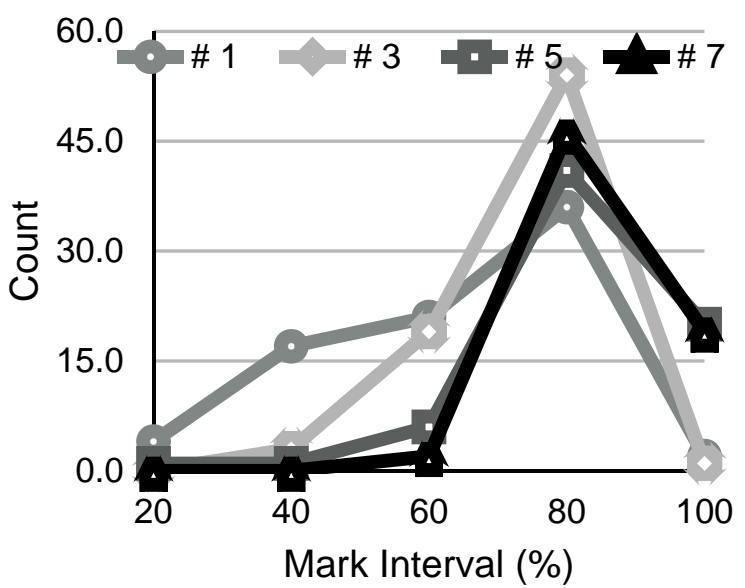

Figure 1: Grade distribution for reflections over four weeks, 1, 3,5 and 7.

average length for the first reflection journal being 409 words. The content of these were mostly focused on describing the technical work done, similar to the findings of Brodie [1]. However, there were also discussions of group dynamics, interpersonal details, time management and how other courses had assisted with knowledge to help complete the project work. From the perspective of the instructor it was informative to read the reflections. Details that could otherwise remain hidden were learned about, including details of group meetings and the level of work outside of the scheduled course hours, frustrations and even interpersonal issues, the latter area being something that may not have been easy to discuss in faceto-face contact. It should be noted that there were a small number of private discussions about group members that occurred between students and instructor.

The marking of the reflections was done online as well with a marking rubric being included as a guide. Here is one way the use of the LMS was helpful to the instructor grading the reflections. The LMS could present the reflection and then the instructor could select through a mouse click one of four options scale for the quality of the reflection and another four point scale for the presentation. Besides each of the two sections (reflection and presentation) a text box was available to include additional instructor's comments.

Because of the number of students, 79 , and the time to read and mark each week, comments and feedback were brief, often pointing out that the student was not reflecting but instead factually describing what was done. The presentation feedback often contained an indication of spelling or grammatical mistakes. Here a 'cut and paste' approach was useful as the students entry could not be directly marked up. The effect of the marking and feedback was to see a move in the overall marking to higher grades over the weeks of the course, as shown in Fig. 1. 
The contribution of the reflection journal to the final grade was $15 \%$, This was a sufficient enough incentive to ensure there was a high number of submissions each week. The highest submission was 76 and the lowest (over the first nine weeks) was 69. Drafting of the reflection could be done in the LMS and the student had to submit the journal. Occasionally there were some students who drafted an entry and who did not submit, usually by oversight or mistake.

\subsection{Survey of opinions}

To gain a better understanding of how the reflection journal was perceived by the students undertaking the course a survey was administered after the final laboratory session but before the examination. The administrator of the survey was one of the authors D P-V., who was not an instructor and had no input on the marking. The response to the survey was $30 \%$, so the results are only an indication of what the whole student group thought of the reflection journal. Finally in the survey there was an open-ended commentary question, which received nine responses, some of which are included in this section. All survey items and response distribution for quantitative questions are presented in Appendix A.

None of the students reported problems with the electronic tool used inside LMS for the submission of journals. The students preferred, however, to draft their journals on their computers first, and only one student typed his or her entries directly into Moodle. This combined with the fact that none of the respondents used paper to draft her/his responses, shows students' familiarity with electronic means of communication.

It is encouraging that the majority of respondents (58 \%) reported that regular journaling improved their reflection skills. Still, when evaluating the effectiveness of the journals in improving their writing skills, their learning of course material, and the journals' helpfulness with the final project, our respondents were divided. Thus, 33\% of respondents felt that reflective journals improved their writing skills, while 25\% thought that journals helped with the final course project and contributed to learning of the course material.

This is strongly expressed in the open-ended commentary question:

"I do have to say that by doing the reflection journal I have a chance to think deeply into what occurred during the week, and sometimes it helped to let out some complains I had, as well as forced me to try to think in different perspectives."

"For people who lack the ability to prioritize themselves, to make good decision, and/or to think critically, I believe this to be a good exercise IF they actually put in the effort to do it.”
"It was a good experience writing reflection journal for the first time, and it was good to remember weekly task we did in the lab. Also it makes you to keep the work done every week rather than leaving it towards to end of semester."

It is interesting to note that almost $21 \%$ of respondents could not decide whether reflective journals were important for their learning, or whether the journals should be used in similar courses. One way to explain these data may be that Engineering students at Carleton University are more projects oriented and are not accustomed to the reflective type of exercise. As some of the respondents noted in the open-ended question:

"Most of the time I don't know what to write, which makes it a burden, because if you don't write anything, you don't get marks."

"The idea that a reflection journal will help us learn about the course is also inaccurate. We have 6 hours a week of labs to analyze what we should be doing with the project and an extra hour to write down our thoughts is not necessary. At that point we are simply regurgitating our thoughts or even simply writing down what the profession wants to see.”

The majority of students (59\%) feel that weekly reflective journaling was a burden and required too much of their time, and $67 \%$ per cent of them would not like to see them introduced in other Engineering courses. As summarized by one of the respondents: "Reflection is good, but doing engineering courses is itself timeconsuming. Sometimes it just feels like extra works that adds onto the anxiety brought by all other homework assignments and test preparations.”

Some of the students voiced their dissatisfaction with the amount of feedback they received for their writing, which is surprising since the detailed grading rubric was used for marking students' journals.

Some of our findings have implications for future teaching practices. In the future, the nature and objectives of reflective journaling need to be made more explicit because students' perceptions of the effectiveness of any of the journaling are important factors that may enhance or inhibit the development of their reflections.

\subsection{Instructor's opinion}

From an instructor's perspective the LMS provided practical benefits over a paper based system. First there was no need to collect and move 79 books or collections of paper. Being able to access the journal entries through LMS via the Internet provided increased flexibility in marking the journals and also provided a degree of security too. The LMS also calculated and compiled the marks automatically, which was another timesaver.

The use of the online rubric helped with the marking. Given the size of the class and the weekly entries, for 13 weeks, the total volume of marking was over 900 entries 
and close to 1000. Comments from students about the brevity of the feedback comments are understandable, but as mentioned the rubric too was to provide comment. As well the instructor did not want to be overly guiding with these personal reflections.

The use of a typed entry did help with legibility. One challenge encountered in the previous year with the paper entries is that the handwritten entries sometimes were difficult to read. This was eliminated with the typed format and the legibility did significantly help with the time it took to read, as well as concentrating on the content. There was a reduction in sketches being included with only a few each week having any diagrams included. The electronic format did help with including photographs and a few submissions included photographs to show parts of their projects.

The quality of the reflections did not appear to suffer with the move from paper to the LMS. Like the previous year there was a range of quality with some good reflections and many that were attempting to reflect but were mostly just recounting what was done during that week on the project. This difficulty in reflecting may need to be examined, perhaps with more resources being provided to illustrate reflection processes.

\section{CONCLUSIONS}

Overall this study shows that the use of a LMS for reflection journals is possible. Indeed there are some practical benefits to the use of the LMS, mostly from the perspective of the instructor. These include easy access, legibility, security, mark calculation and compilation and the easy inclusion of photographs.

The study also shows the perceived burden on the students. This perception may be increased due to the challenge some students may have in understanding the purpose of the reflection. Many of these reflections did not extend beyond descriptions of the work done on the project during the week. A few students did understand the potential of reflection and some entries provided some good insight into their experiences and understanding of their work.

The finding from this course is that next year the use of the LMS for reflection journals can be used. The burden of the workload, both for the student and instructor, could be mitigated by moving to a two weekly submission requirement rather than one. However, that slows down feedback and makes each entry more significant in the overall marking scheme. As well, this could also reduce the reflection cycle of the student. This will need to be considered, but the benefits may outweigh the delayed cycle.

\section{Acknowledgements}

We would like to thank Carleton University's students enrolled in ELEC 3907A in winter 2014, and Prof. Q.J. Zhang, who co-taught this course with Professor Steele.

\section{References}

[1] Lyn Brodie, "Reflective writing by distance education students in an engineering problem based course," Australasian Journal of Engineering Education, vol. 13 (2), pp. 31-40, 2007.

[2] Stephen Brookfield, Developing Critical Thinkers: Challenging Adults to Explore Alternative Ways of Thinking and Acting. San Francisco, CA: Jossey-Bass, 1987. \{ISBN: 1-55542356-6\}

[3] John Cowan, "Noteworthy matters for attention in reflective journal writing," Active Learning in Higher Education, vol. 15(1), pp. 53-64, 2013.

[4] John Dewey, How We Think. Mineola, NY: Dover Publications, 1997. Originally published Boston, MA: D. C. Heath, 1910, re-published 1933. \{ISBN: 0-486-29895-7\}

[5] Peter Jarvis, "Reflective practice and nursing," Nurse Education Today, 12, pp. 174-181, 1992.

[6] Ference Marton, and Roger Säljö, “On qualitative differences in learning: Outcome and process,” British Journal of Educational Psychology, 46, pp. 4-11, 1976.

[7] Jack Mezirow, Fostering Critical Reflection in Adulthood: A Guide to Transformative and Emancipatory Learning. San Francisco, CA: Jossey-Bass, 1990. \{ISBN-1-55542-207-1\}

[8] Jennifer Moon, "Learning journals and logs, reflective diaries," Good Practices in Teaching and Learning. University of Exeter, January 2010. Available as of April 3, 2014 from http://www.deakin.edu.au/itl/assets/resources/pd/tlmodules/teaching-approach/group-assignments/learningjournals.pdf

[9] Stuart Palmer, Dale Holt, and Sharyn Bray, "The learning outcomes of an online reflective journal in engineering," in Proceedings ascilite (Melbourne, Australia, June 6-8 2008) pp. 724 -732, 2008.

[10] Carl Reidsema, Rosalie Goldsmith, and Pam Mort, "Writing to learn: reflective practice in engineering design," American Society for Engineering in Education, 2010.

[11] Carol Rodgers, "Defining reflection: another look at John Dewey and reflective thinking," Teachers College Record, vol. 104 (4), pp. 842-866, 2002.

[12] Donald A. Schön, Educating the Reflective Practitioner. San Francisco, CA: Jossey-Bass, 1987. \{ISBN: 1-55542-220-9\}

[13] Elizabeth Smith, Julie Mills, and Baden Myers, “Online learning techniques: using wikis and blogs for assessment in first year engineering," in ATN Assessment 08: Engaging Students with Assessment, 2008. 


\section{APPENDIX A: REFLECTION SURVEY RESPONSES}

A 5 level Likert scale was used for most questions, with the levels being, strongly agree (SA), agree (A), undecided (U), disagree (D) and strongly disagree (SD). The questions and results (rounded to the nearest percentage so the total may not exactly equal $100 \%$ ) were as follows. Of the 79 students in the course 24 responded, a $30 \%$ response rate.

Weekly reflective journals in this course helped with the course final project: SA 4\%, A $21 \%$, U 21\%, D 33\%, SD $21 \%$.

Writing reflective journal every week was a burden and took too much of my time: SA $17 \%$, A $42 \%$, U $21 \%$, D 21\%, SD 0\%.

Weekly reflective journals helped improve my writing skills: SA 4\%, A 29\%, U 29\%, D 29\%, SD 8\%.
Weekly reflective journals helped improve my reflections: SA $8 \%$, A 50\%, U 0\%, D 25\%, SD 13\%. (One student did not respond).

Weekly reflective journals contributed to my learning of the course material: SA $0 \%$, A $25 \%$, U $21 \%$, D $46 \%$, SD 8\%.

It would be useful; if other Engineering courses also require regular writing of reflective journal: SA $0 \%$, A $13 \%$, U 21\%, D 42\%, SD 25\%.

Another question did not use the Likert scale and instead enquired about the approach of writing the journal.

How did you MOSTLY write your reflection journals?

Directly into the LMS without drafting 4\%

Drafting and submitting after rereading and possible revisions $0 \%$

Writing in a separate application like a word processor or text editor $96 \%$

Drafting out on paper and then typing into the LMS $0 \%$ 